\title{
Healthcare Provider and Patient Dispute: From Prevention to Restoration-the Neccessity of Communication and Caring
}

\author{
Yong-Chi Chen", Shih-Ying Lee \\ Chen Chung Chwen Memorial Doctor-Patient Relationship Promotion Educational Public Welfare Trust Fund(CDPET), Taipei, Taiwan

\section{Email address:} \\ cyclee168@kimo.com (Yong-Chi Chen), cyclee1688@gmail.com (Shih-Ying Lee)
}

\section{To cite this article:}

Yong-Chi Chen, Shih-Ying Lee. Healthcare Provider and Patient Dispute: From Prevention to Restoration- the Neccessity of Communication and Caring. American Journal of Clinical and Experimental Medicine. Vol. 3, No. 5, 2015, pp. 310-313. doi: 10.11648/j.ajcem.20150305.30

\begin{abstract}
This article is meant to discourse the idea and skill of communication and care that is fundamental to the prevention as to restoration from dispute between healthcare provider and patient (DHP). DHP can be separated into 3 steps of intervention, thus 1. internal hospital negotiation; 2. external hospital mediation from Bureau of Health, medial association, city government mediation committee or arbitration; 3. Court litigation or mediation. Then, we introduced the current models of these 3 steps in Taiwan and Internal Hospital Mediator (IHM) model known as Japanese style, a form of medical alternative dispute resolution (ADR). Different ability of communication and care can be used in different situations as self-mediation, onsite correspondence, and professional mediation. Finally, how IHM can be of use as intervention principle and methods to 7 scenarios of physician-patient relationship.
\end{abstract}

Keywords: Medical Dispute, Communicating Caring, Internal Hospital Mediator, Mediation, Healthcare Provider and Patient Dispute, Alternative Dispute Resolution

\section{論醫病爭議的預防到修復一談溝通關懷存在的必要}

\author{
陳永綺*, 李詩應 \\ 陳忠純紀念促進醫病關係教育公益信託推廣會, 臺北市, 臺灣 \\ 邮箱 \\ cyclee168@kimo.com（陳永綺）, cyclee1688@gmail.com（李詩應）
}

摘要: 本文就醫病爭議來論述預防到修復醫病關係不良所必需要的溝通關懷理念與技巧。論述目前相關臺灣處理醫病 爭議模式。接著介紹日本特有院內促進溝通調解模式, 性質上屬於醫療糾紛訴訟外處理機制。不同層次溝通關懷能力 可以應用的場合有自我、現場對應及專業上的溝通關懷。最後論述其可以介入醫病關係上的七個時機之不同原則及方 式。唯有溝通關懷從預防醫病關係的破裂到修復均有著力之處, 由此也顯見其必要性。

关键词：醫療糾紛，溝通關懷，促進溝通調解，調解，醫病爭議，醫療糾紛訴訟外處理機制

\section{1. 引言 \\ 醫療糾紛的定義依醫療糾紛處理辦法及補償條例草 案 [1] 第 3 條第 1 款: 「指病人認醫療行為有不良結果,}

而應由醫事人員或醫療 (事) 機構負責所生爭議。」而 醫療爭議雖見於醫療爭議調處要點但並未下定義, 通常 認為係包括: 1. 較輕的不滿申訴; 2. 較重的發生醫療行 為不良結果; 3. 到最重的發生醫療事故的醫療糾紛都涵 蓋在內。本文以醫病爭議為標題主要目的是, 因為這樣 
包含範圍最為廣泛，包括不滿申訴及醫療糾紛處理辦法 及補償條例草案所定義的醫療糾紛，不僅限於狹義醫療 糾紛一發生醫療事故這種屬於重大事件包括重大傷亡結 果, 通常需要第三方協力機構團體介入的事件而已。且 篇名帶有修復，因此要強調的是醫病關係，而不適合使 用醫療爭議或醫療糾紛。

「調解」一詞, 很容易被認為是一般傳統的「對立的隻 方請一位第三人幫忙解決爭議的制度」。「醫療促進溝通調 解」是日本和田仁孝教授與中西淑美副教授二人所共同提倡 的的理論與概念, 最初的名稱來源為「醫療mediation」。 在我們陸續赴日引進臺灣的最初翻譯名詞出來後, 也曾多次 被質疑也被誤認為是一般傳統的調解, 因此將「醫療促進溝 通調解」定名為「醫療溝通關懷」以和一般傳統的調解做一 個區隔, 性質上屬於醫療糾紛訴訟外處理機制 [2]。此外, 許多人亦將此概念僅限於醫療診所院內的溝通調解。事實不 然, 因為醫療溝通關懷是適用各種溝通場景的對話模式, 並 不是只局限於醫院內溝通調解的單一場合而已。雖然在日本, 院內醫療溝通關懷員只能限醫療機關職員, 這是由於日本律 師法的關係。在臺灣, 目前尚無正式的溝通關懷員制度, 因 此對此並無明文的限制。

實際上溝通關懷, 是一個概念, 可以應用的範圍非常 的廣泛, 在各種醫療場景中, 只要有溝通關懷的想法任何 人、事、時、地都能派上用場。和田教授書中一再強調, 也是強烈的主張：「無論何時、何地、任何具有溝通關懷 思惟的人都能從事溝通關懷, 這也是醫療安全、安心的對 話模式。」由此可知, 溝通關懷不僅只能應用在醫療事故 的對應上, 尤其是醫師本身也可以應用於病患與醫療人員 間或是醫護人員間的各種溝通場景的對話。 [3]

醫療溝通關懷員並非只在醫療事故發生後才出面, 很多情況如知情同意、日常的診療對話或是醫療資訊公 開對話等, 溝通關懷的想法在各種醫療場景中, 都能派 上用場; 這是醫療溝通關懷的主軸。因此我們必須在此 再三強調醫療溝通關懷, 並不只局限於事故發生後的應 對。溝通關懷是可以在任何人, 事, 時, 地等都得以運 用的方法, 從預防事故發生到關係的修復, 溝通關懷都 有其著力的地方。

\section{2. 材料和方法}

現有醫療爭議處理模式而言, 事實上跟所有專業一樣, 都是針對「事」的處理, 卻缺少了對「人」的關懷。也因 此常常會造成給人冷酷無情, 不把人當人的感受而導致怨 聲載道四起。甚至有一點小事動不動就提起告訴的情況越 來越明顯的趨勢。［5]透過對目前台灣醫療爭議處理現 況的了解及引進日本院內醫療調解理念來思考在台灣如 何落實醫療爭議之關懷式調解是本研究課題目標。

\section{1. 臺灣現有醫療爭議處理模式三階段}

針對臺灣現有的醫療爭議處理模式主要有下列三階段:

\subsection{1. 醫院内: 以雙方交涉為主}

通常又分為較輕的醫療申訴及較嚴重的醫療糾紛兩 種。醫療爭議常發生在病方對於醫療或醫療作業過程有所
不滿時, 藉由醫院的客服中心或相關單位投訴, 經代表醫 方的相關人員與家屬或病方進行溝通瞭解, 若雙方合意 (即互相對對方所提解決方案滿意而接受), 就於院內自 行處理結案。倘若病方對處置難以滿足或不合意或院方置 之不理, 此時, 病方通常會另尋管道, 以進行其下一步的 處理方式來抒發其不滿的情緒。至於較嚴重的醫療糾紛, 則偶而會先在院內提出, 大部分直接在院外提出或直接至 法院提起告訴。

\subsection{2. 醫院外: 第三方協力機構團體介入, 有各式調解、 調處或仲裁}

經由向衛生局提出申訴或調處、醫師公會或鄉鎮市請 求調解、或合意向仲裁協會申請仲裁。醫師公會與衛生局 或鄉鎮市都設有調解（調處）申訴的視窗，民眾會因院內 交涉失敗不滿而再進一步甚或會直接向這些單位投訴或 請求。

綜觀臺灣衛生單位統計, 向衛生局、各地醫師公會申 請案例時有所聞, 申請調處案件2013年統計臺北市、新北 市 (1-10月)、台中市各約106、73、40件，結果大約各是 $39 \% 、 61.7 \% 、 35 \%$ 的成功率。 $[6-7]$

各鄉鎮市調解會的一般案件調解成功率, 1998年臺北 市、高雄市、台中市各是35\%、24\%、50\%左右，而2005年 高雄市統計成功率達60. 4\%, 至2007年則高達70-76\%左右。 [8-10] 但醫療糾紛調解因為並未獨立採計, 所以無從得 知。但因為事後須向法院申請, 據法院方面表示案件數不 多, 大多是偏遠地區受到民代壓力而實行的為主。 [11]

然而雖然目前醫師仲裁人已有 65 人, 但據悉採取醫療 仲裁的案件至目前為止的統計, 則是掛零。可能原因分析 如下：1. 整體仲裁體制仍有許多問題導致甚多疑慮; 2 . 醫療糾紛系涉及高度情緒問題的爭議特性, 不適合仲裁程 式解決; 3. 一般民眾及多數醫事人員對仲裁程式完全不瞭 解； 4. 其他原因等。 $[12-13]$

\subsection{3. 法院: 主要以訴訟為主, 亦設有法院調解一環}

訴訟是解決糾紛的最後手段, 醫療糾紛訴訟主要分為 民事及刑事兩種。醫療糾紛在民事上依民訴第 403 條第 1 項第7款規定屬強制調解先行。而目前在醫療糾紛處理辦 法修法中, 也在重申訴訟前調解前行規定, 因此向法院提 起告訴之前, 必須先自行調解或在法院內先進行調解。刑 事上, 目前並無強制調解先行法律規定, 但一般會先勸雙 方和解, 再依和解成立與否, 作為檢察官決定及法官審理 之重要判斷因素。行政院版醫療糾紛處理及醫療事故補償 法草案只針對醫糾民事案件規定增加訴訟外解決機制之 選擇性, 未針對刑事案件規定, 雖然其他版本或有提及, 但爭議不小，目前尚無定論。［14]

對病方而言, 上述的的三階段常不是按部就班而來的 步驟。甚至在臺灣之醫療糾紛處理曾經常欲藉以刑逼民, 而直接採刑事告訴附帶民事的訴訟方式, 卻導致最後裁判 結果出來時, 雙方都不能滿意的雙輸局面。關於上述三階 段的醫療糾紛處理現況包括以刑逼民為主的情形已經改 變, 詳細論述請另參考拙著: 醫療糾紛調解臺灣現況與展 望。 [15] 


\section{2. 醫療糾紛處理日本特有模式簡介}

在日本, 2003年起設立了針對避免上述訴訟導致的雙 輸的一種醫療人員培訓課程, 這是經由一位醫療失誤死亡 的家屬佐佐木太太的經歷分享, 加上法學教授和田仁孝先 生以及當時的大學醫學部中西淑美老師三人合作，首先提 出了日本『院內溝通關懷』的制度, 這是與美國賓州以及 密西根大學的經驗相類似, 經過多年努力, 為日本訓練出 上千位的溝通關懷員，並著實地為日本減少了醫病法三方 的負擔與糾結, 進而得以創造了一個符合人性需求的醫療 安全, 安心的對話模式與建立安定醫病關係制度, 終於達 成創造三贏的局面。 [16-18]

\section{3. 醫療溝通關懷的種種面向}

分析醫療溝通關懷的目的, 並非只在避免訴訟, 更非 單純地只想是要達成和解（甚或金錢賠償）與停止紛爭。 因為如此僅是傳統式「解決糾紛」的狹義思考模式而已。

醫療溝通關懷, 應該是強調提供讓患者與醫療人員得 以面對面的一個機會, 並進而促進當事人對話溝通的導航 過程。更重要而與以往不同的是,並不要求問題(壹時性) 解決了没有, 而是醫病雙方對話的過程與資訊得以公開, 以及共有的經驗分享。我們希冀透過這樣促進對話溝通的 方式, 協助患者與醫療人員得以修復已經破裂而恢復過往 的, 甚或建立更良好關係, 這也是醫療溝通關懷所寄予的 理想, 也是最大目標。

在操作上, 醫療溝通關懷員的角色是在於促進並製造患 者與醫療人員面對面溝通的機會和空間。並不會代為轉達醫 師與醫方的醫療建議, 亦不會代為轉達患者的意見, 因為讓 雙方當事人面對面的溝通才是必要的, 也才能在當事人對話 當中, 找到方向看見解決的出口, 然後自我療癒。這就是當 前惡劣醫療環境的極限裡, 溝通關懷的最重要的意義所在。

另外, 醫療溝通關懷員也不會代為轉告患者院內事故 調查委員會等檢討會結果及相關的賠償提案。必須重複強 調的是: 醫療溝通關懷員的角色並不是代理人, 而是在協 助促進患者與醫療人員雙方的對話。在雙方的對話中, 獲 得彼此需要的寶貴資訊, 進而能夠更進一步的達成雙方的 真正需求, 並徹底化解糾紛修復關係。

\section{3. 結果與討論}

\section{1. 學習溝通關懷並非僅只應用於調解}

醫療溝通關懷所在乎的不祇是技巧, 更需強調其態度。 當理解理念並學習到技巧時! 並不代表就是完成, 而只是 一個開始, 接下來要不斷的練習, 將技巧融入於心, 發自 內心的自然表現在態度上, 身體力行, 如影隨形, 如此才 能算是專業稱職的溝通關懷員。

因此, 何以需要各種不同階段的溝通關懷課程學習, 也就是為了要讓這樣的技巧不斷思考與練習, 做到爐火存 青的程度, 將來面對重大的問題時, 能夠因應如宜、不害 怕、不退卻，都能以同理心傾聽與應對，讓當事人雙方因 為專業的溝通關懷員的協助開創對話, 透過事實的主張、 感情的主張、要求的主張等邏輯的分析與思考, 在對話中,
讓雙方自我覺醒、借著這樣的對話「空間」, 引導出瞬間 的心意相通或某種「創造」的交會, 無形的建立起雙方的 信賴與朝向好的方向前進。

隨著技巧與經驗的累積, 溝通關懷的能力也就有了層 次的差異, 可以應用於各種的場合：「自我溝通關懷 (Self Mediation)」、「現場對應溝通關懷」、進而「專職醫療 溝通關懷員負責的醫療溝通關懷」。 [19]

\subsection{1. 「自我溝通關懷(Self Mediation)」}

適用的場合常為第一線的醫療人員, 如1. 醫師平常 診療、2. 護理人員照護病人、3. 醫檢人員、行政人員等等, 是醫療人員面對自我衝突管理與基本的一對一溝通關懷 技巧。

\subsection{2.「現場對應溝通關懷」}

其適用的場合, 常是需要當事人雙方與溝通關懷員在 一處的場合屬之，舉例說明，如在「告知後同意」的情況 下進行醫療促進溝通調解, 能確保病方的發言機會, 並促 進雙方基於其背景或環境的對話與互相瞭解; 又當醫療事 故或投訴等問題擴大發展時, 在當場所需要鄰近可適時介 入溝通關懷員 (例如受過訓練的護理長等) 的發揮其調解 技巧與理論來應用於各種醫療情境, 這可以說是醫療糾紛 或事故的極早期介入。

\subsection{3. 「專職醫療溝通關懷員負責的醫療溝通關懷」}

然在醫療崩壞, 醫病關係逐趨緊張的臺灣, 專職醫 療溝通關懷員負責的醫療溝通關懷的適用場合, 則屬重大 案件發生時, 或如病人發生重大傷害或死亡的結果時, 所 致之重大醫療糾紛發生, 因為此階段所涉不僅情緒傷痛慘 烈難以平撫, 同時也複雜的涉及不同單位與處理人士, 涵 蓋了醫院外的所在衛生單位, 各地醫師公會與在地之鄉鎮 市區公所的調解會之一個層級甚至是法院前之調解。

\section{2. 溝通關懷的切入時機}

溝通關懷是動態發始, 持續關懷, 隨機起動的思維, 亦絕非在發生於醫療事故時, 才單純地開始想到發動溝通 關懷員去處理事故的調解。如果硬要分出適當的切入時機 的話, 大概可以說明於下:

Step1-醫療行為之說明溝通: 在說明溝通時, 醫方如 有病方為主的溝通意識及技巧, 便能容易的形成雙方對醫 療決定的共識, 減少或預防日後糾紛的產生。此種以病方 為主的溝通意識及技巧可於溝通關懷相關學習而得。

Step2-早期覺察醫病關係嫌隙: 在人際關係四階段中, 早期的分離階段通常不明顯, 學習溝通關懷的三大技巧之 一: 察覺力, 可以提升這方面的能力, 及早看到問題, 及 時介入, 事半功倍。

Step3-爭議開始浮現: 有爭議之醫方本人, 習得溝通關 懷, 可以傾聽對方並給予同理心的支援、分析其隱藏的欲求, 嘗試促進溝通以瞭解對方的真正需求來尋求雙方達成共識。

Step4-爭議事件需要院內第三人現場介入: 院內同事, 曾經習得溝通關懷之人, 可以傾疆雙方、給予同理心的支援、 分析雙方各自隱藏的欲求, 並嘗試促進溝通以達成雙方共識。 
Step5-爭議事件牽涉醫療安全問題需要賠償道兼等 較大問題，需院方出面：院內訓練有素之溝通關懷員，可 以對雙方傾聽、同理心的支持、分析雙方各自隱藏的欲求, 並嘗試促進溝通以達成雙方共識。

Step6-爭議事件擴大至院外調處、調解：在這階段, 可請第三方協力機構團體或是院內專職之溝通關懷員出 面對雙方傾聽、同理心的支持、分析雙方各自隱藏的欲求, 並嘗試促進溝通以達成雙方共識。或是作為調處、調解之 前階段作業, 彌平雙方情緒上之不滿或害怕, 來促進溝通, 為後續調處或調解作準備, 以提高成功率或化解部分爭執 減少爭議案件及爭議強度。

Step7-訴訟: 訴訟時已經建立信賴關係的溝通關懷員 仍然可以陪伴, 安慰及協助心理層面的療癒, 將問題去除 情緒影響而簡單化。

\section{4. 结論}

最後, 我們必須再次強調溝通關懷, 絕不是一般只停 留在院內的交涉一溝通調解現場上的舊思維而已。而是, 需要能夠對溝通關懷的理念與技巧善加應用, 更深入瞭解 與學習。他有增加醫方與病方協同治病、預防糾紛發生、 防止糾紛擴大、弭平糾紛、及修復破裂關係的作用, 符合 現代醫學以病人為中心的醫療趨勢。[20] 由此觀之, 其 必要性冉庸置疑, 我們期待引進與積極推廣這樣的理念與 培訓課程能夠對改善醫療的環境盡一分心力。

\section{参考文献}

１１］醫療糾紛處理辦法及補償條例草案 [ Z ] , 參 http://www. tma. tw/bi1l/bil1_files/121\%E8\%A1\%8C\%E6\% 94\%BF\%Е9\%99\%A2\%Е7\%89\%88\%Е9\%86\%AB\%Е7\%99\%82\%Е7\%B3\%BE \%Е7\%B4\%9B\%Е8\%99\%95\%Е7\%90\%86\%Е5\%8F\%8А\%Е9\%86\%AB\%Е7\%9 9\%82\%Е4\%BA\%8B\%E6\%95\%85\%Е8\%A3\%9C\%Е5\%84\%9F\%E6\%B3\%95\% $\mathrm{E} 8 \% 8 \mathrm{D} \% 89 \% \mathrm{E} 6 \% \mathrm{~A} 1 \% 88 . \mathrm{pdf}$, 最後檢視日2015/11/09。

［2］李詩應, 日本促進醫療和諧訓練課程學習之旅 [J], 臺灣 醫界，2013，Vol.56（No.6）：頁55-58。

[3] 和田仁孝, 医療メデイエション最前線, Part 4 Q\&A[ J ], 醫療安全, Dec. 2008, Vol.5 (No. 4)：頁32-37。

［4］和田仁孝、中西淑美著, 醫療促進溝通: 由敘事著手的衝 突管理 $[\mathrm{M}]$ ，黃羿文、李訓承等翻譯, 臺北市, 原水文化 出版, 2013/11/14。

[5] 抽血瘀青怒告醫檢師不起訴 [ N ] 。參 http://www. appledaily. com. tw/realtimenews/article/ new/20141201/516289/, 最後檢視日2015/11/09。

[6] 臺北市及新北市調處申請案件數 [C ] , 請參2013年5/18 舉行之臺北醫法論壇 (IX) 醫療糾紛處理法制與兩岸比較, 講義資料, 頁 $135-147$ 。

[7] 劉家正, 臺北市衛生局美容醫學醫療糾紛調處經驗分享 $[C]$ 。 2014「醫療安全與醫療糾紛系列講座」一「美容醫學安全
與醫療爭議態樣及調處經驗分享」研討會, 2014年8月 17 日，研討會資料，頁33-34。

[8］醫療糾紛調解機制各地經驗分享研討會 [J], 臺灣醫界, 2014, Vol. 57, No. 5, 頁25-36。

[9] 顏福瑞, 消費爭議調解制度之研究-強制調解之可行性 [D], 高雄市: 國立中山大學管理學院EMBA碩士論文, 2001.7。

[10］高雄市調解業務統計分析報告 [ R ], 高雄市民政局報告, 2006. 9

https://encrypted. google. com/search?h1=zh-TW\&sourc $\mathrm{e}=\mathrm{hp \& q}=$ 高雄市調解業務統計分析報告\&gbv=2\&oq=高雄市 調 解 業 務 統 計 分 析 報 告 \&gs_1=heirloom-hp. 12. . 3502. 25960. 0. 27867. 54. 17.6. 31. 26. 0. 864. 1968. 12 j3 j6-1. 16. 0. msedr. . 0. . . 1ac. $1 \mathrm{j} 4$ . 34. heirloom-hp. . 33. 21. 1823. nAo01dHi6gE ，最後檢視 日2105/11/09。

[11］張嘉真, 洪舒萍, 臺灣調解制度之簡介與比較 [ J ] , 萬 國法律，2009/2（No. 163）：頁55-66。

[12］郭英調, 醫療糾紛適合仲裁 [R], 衛福部醫療爭審報導, 2009/1

http://www. mohw. gov. tw/dmc/admin/UpFile/Period38/0 2醫療糾紛適合仲裁. pdf ，最後檢視日2015/11/09。

[13] 台大教授知財貪財 $-A$ 兩億只罰一百萬 $[\mathrm{N}]$, http://bluestapler. pixnet. net/blog/post/25631520-\% 5B中時\%5D, 最後檢視日2015/11/09。

[14] 林萍章, 醫療調解前置主意之爭議 [ J ] , 月旦法學, 2013/5 (No. 216)：頁62-86。

[15］李詩應、陳永綺。臺灣醫療糾紛調解現狀與展望 [C ], 發表於2014/10/25-26南京舉行之第五屆海峽兩岸醫藥法 學術研討會論文集, 頁115-120。

[16] 李詩應、陳永綺著, 當醫療遇上衝突糾紛, 訴訟是最好的 解決方法? [M] 臺北市, 原水文化出版社, 2013/10/24。

[17] Carol B. Liebman and Chris Stern Hyman. A Mediation Skills Model to Manage Disclosure of Errors and Adverse Events to Patients. [ J ]Health Aff. July 2004, vol. 23, (no. 4) : P. 22-32.

[18] Richard Boothman, Amy Blackwe11, Darre11 A. Campbel1, Jr., Elaine Commiskey, and Susan Anderson. A Better Approach to Medical Malpractice Claims? [J] The University of Michigan Experience. Journal of Health \& Life Law 2009, vol. 2 (No. 2): pp. 125-159.

[19] 李詩應, 陳永綺, 促進醫療溝通調解的理想與未來一提升 醫療安全與醫療品質之重要且不可或缺之一環 $[\mathrm{J}]$, 臺灣 醫界，2015，Vol.58(No. 11)：頁55-58。

[20] Tammy C. Hoffmann, PhD; Victor M. Montori, MD, MSc; Chris Del Mar, MD, FRACGP. The Connection Between Evidence-Based Medicine and Shared Decision Making. [ J ] Viewpoint | October 1, 2014, JAMA. 2014; 312 (13) : 1295-1296. 